\title{
Near-IR Quantum Cutting Phosphors: A Step Towards Enhancing Solar Cell Efficiency
}

\author{
Abhijit P. Jadhav ${ }^{\mathrm{a}}$, Sovann Khan ${ }^{\mathrm{a}, \mathrm{b}}$, Sun Jin $\mathrm{Kim}^{\mathrm{a}}$, and So-Hye Cho ${ }^{\mathrm{a}, \mathrm{b}_{*}}$ \\ ${ }^{a}$ Center for Materials Architecturing, Korea Institute of Science and Technology (KIST), Seoul 136-791 \\ ${ }^{b}$ Department of Nanomaterials Science and Engineering, Korea University of Science and Technology, Daejeon 305-350 \\ (Received September 24, 2014, Revised September 30, 2014, Accepted September 30, 2014)
}

\begin{abstract}
The global demand for energy has been increasing since past decades. Various technologies have been working to find a suitable alternative for the generation of sustainable energy. Photovoltaic technologies for solar energy conversion represent one of the significant routes for the green and renewable energy production. Despite of remarkable improvement in solar cell technologies, the generation of power is still suffering with lower energy conversion efficiency, high production cost, etc. The major problem in improving the PV efficiency is spectral mismatch between the incident solar spectrum and bandgap of a semiconductor material used in solar cell. Luminescent materials such as rare-earth doped phosphor materials having the quantum efficiency higher than unity can be helpful for photovoltaic applications. Quantum cutting phosphors are the most suitable candidates for the generation of two or more low-energy photons for the absorption of every incident high-energy photons. The phosphors which are capable of converting UV photon to visible and near-IR (NIR) photon are studied primarily for photovoltaic applications. In this review, we will survey various near IR quantum cutting phosphors with respective to their synthesis method, energy transfer mechanism, nature of activator, sensitizer and dopant materials incorporation and energy conversion efficiency considering their applications in photovoltaics.
\end{abstract}

Keywords : Quantum cutting, Near-infrared, Phosphor, Luminescence, Energy transfer

\section{Introduction}

Every living organism is associated with energy, which is required for various life functions. With the development of human race, the amount of energy required was increased enormously due to the invention of its application in various processes. Energy is the basic source for running different types of machinery, vehicles and for the generation of light which we receive through electric bulb or tubes. The different type of natural energy resources are wind power, solar energy, geothermal energy, hydroelectric power, biofuels, natural gas, fossil fuel and nuclear energy. The only common thing in all natural resources is their limited availability. Due to excessive use most of the natural resources are about to finish and the need for sustainable source of energy has become highest priority for all of us.

* [E-mail] sohyec@kist.re.kr

This paper was presented at IMCM 2014. 
Sun, being an abundant source of energy, has always remained the major and continuous source of energy supply for the prolonged time span. A series of nuclear fusion reaction occurring on the surface and bulk of sun produces energy which is generated mainly in the form of electromagnetic radiations in the spectral range of $0.2 \sim 3 \mu \mathrm{m}$. Out of the energy received by Earth, approximately 30\% is reflected back to space while $70 \%$ of the energy is absorbed by clouds, oceans and earth's surface. The spectrum of the solar light reaching earth's surface is mostly spread across the visible and near-infrared regions and very small part in near-ultraviolet range.

Solar spectrum is consisted of photons distributed over a range of energy. Higher energy photons (energy higher than the band gap energy) can excite electrons from the valance band to conduction band where they can exit the device to generate electrical power. Lower energy photons though failed to excite valance band electrons, travels through the solar cell and they get absorbed at the rear end of solar cell in the form of heat. The inherent thermalization and nonabsorption losses can be reduced to minimum with the incorporation of luminescent materials as spectral converters. The approach, termed the third-generation solar photon conversion, involves the in-

corporation of a passive luminescent layer into photovoltaic cells [1]. The important reason for the application of spectral converters in existing solar cell technology is their compatibility with each other with minor changes.

Three luminescence processes including up-conversion, quantum cutting and down-conversion/ down-shifting are the important topics of research for the development of photovoltaics. Trivalent lanthanide ions are the most suitable candidates for the effective spectral conversion due to their rich energy level structure which is also known as Dieke diagram, that allows for facile photon management. In this review, we will focus mainly on quantum cutting materials since they have drawn much attention lately due to their high quantum efficiency property [2-4].

\section{Quantum Cutting Phenomenon}

\section{Visible quantum cutting}

The concept of quantum cutting provides a useful means to obtain two or more number of photons for every absorbed photon. The visible quantum cutting phosphors which utilize the vacuum UV (VUV) light

(c)

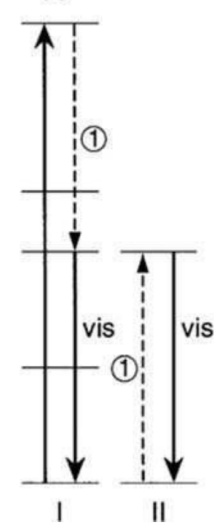

(d)

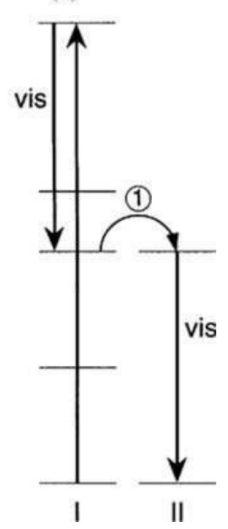

Figure 1. Energy level diagrams for two imaginary types of rare earth ions (I and II), showing the concept of down-conversion. Type $I$ is an ion for which emission from a high- lying level occurs. Type II is an activator ion to which energy transfer takes place. (1) and (2) denote energy transfer steps, as copied from ref. [6]. 
to generate visible light with conversion efficiency greater than unity help to provide improved energy efficiency in lighting devices [5].

The energy of vacuum UV (VUV) photon is much higher than the energy of visible photon which makes it capable of generating two visible photons when absorbed. The process of generation of two photons from the absorption of single photon is known as quantum cutting (QC), quantum splitting (QS) or photon cascade emission (PCE). Wegh et al. illustrated the energy level diagram for two types of rare earth ions (I and II) showing the concept of down-conversion phenomenon [6]. Theoretically, efficient visible $\mathrm{QC}$ via two photon emission from high energy level for a single rare earth ion is possible and is represented in Fig.1a. The competing emission in the IR and UV range indicated by thin lines in Fig. 1a can be responsible for the efficient $\mathrm{QC}$ on a single rare earth ion. Fig. 1b-d show generalized energy level diagram for three possible down-conversion mechanisms involved with energy transfer between two different rare earth ions I and II where type I indicates ion in which the emission occurs from high lying level and type II indicates an activator ion to which energy transfer takes place. Energy level dia- gram $2 \mathrm{~b}$ shows two photon emission from ion pairs taken through cross relaxation and electron transfer modes between ions I and II as indicated by (1) and (2). A cross relaxation mechanism followed by emission of photons takes place from both ions I and II (indicated in Fig. 1c). In all above mentioned cases if the two step electron transfer process is energetically efficient then we can observe visible quantum efficiency of as high as $200 \%$ due to prevention of energy degradation through IR and UV losses existing in a single ion [7].

\section{Near IR (NIR) quantum cutting}

The process of NIR quantum cutting is involved in the generation of two NIR photons for each visible photon absorbed. The NIR quantum cutting phosphor materials are particularly useful for $\mathrm{Si}$ solar cells since the band gap of $\mathrm{Si}$ is $1.1 \mathrm{eV}$ which falls in NIR region. When the energy lost by thermalization is converted to NIR by quantum cutting, they can contribute solar-cell efficiency significantly. The different mechanisms involved for the NIR quantum cutting are illustrated in Fig. 2.

Fig. 2 represents summary of NIR quantum cutting

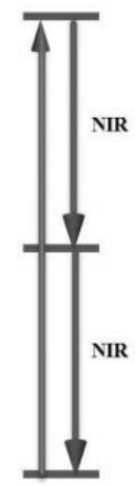

(I)

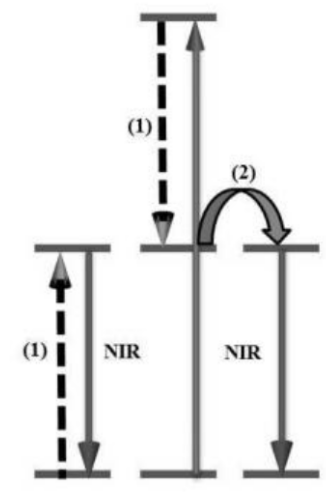

(II)

(I)

(II)

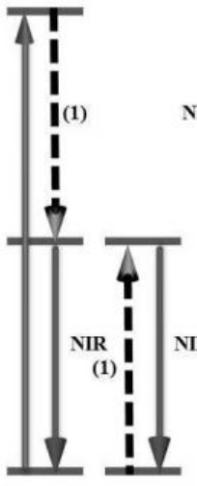

(I)

(II)

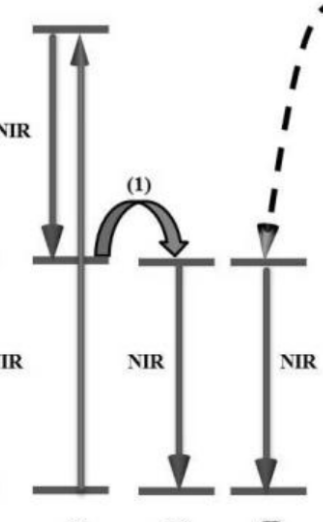

(I)
(II)

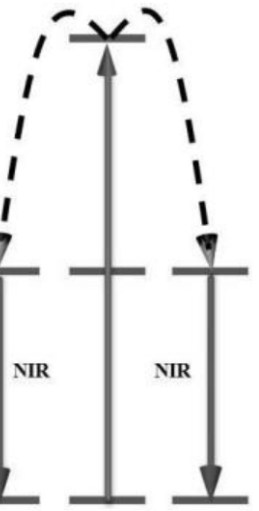

(I)

Figure 2. Energy level diagrams for ions (types I and II) are given to illustrate the concept of NIR quantum-cutting. (a) NIR quantum-cutting on a single ion by the sequential emission of two NIR photons. (b-d) NIR quantum cutting due to resonant ET from ion I to ion II. (e) NIR quantum-cutting due to cooperative ET from ion I to ion II. Note that two type II ions simultaneously emit two photons in the NIR spectral region [8]. 
mechanism. The first mechanism shown in Fig. 2a is responsible for NIR quantum cutting consists of one luminescent center with 3 different energy levels, consists of ground state, intermediate energy level and higher energy level state. The sequential generation of two NIR photons is possible after the electronic transition of optically active electron to its highest energy level by the absorption of one UV or visible photon. The generation of photon takes place when an electron from highest energy level jumps to intermediate energy level, which remains populated for short period of time before further electronic transition to ground state level with a generation of another NIR photon. NIR quantum cutting has been reported with single ions like $\mathrm{Ho}^{3+}, \mathrm{Er}^{3+}$ and $\mathrm{Tm}^{3+}$, respectively [9-14]. The emission of NIR photons may get the setback from the unwanted emissions in the UV-visible region along with non-radiative recombination along with desired NIR emission.

To overcome the problem of unwanted emissions and non-radiative recombination, the alternative mechanism for NIR quantum cutting was proposed which include incorporation of two luminescent centers. The mechanism is summarized in Fig. 2b. A possible mech- anism of quantum cutting occurs through two-step electron transfer from an ionic pair of lanthanide ions, followed by emission of two NIR photons. NIR quantum cutting has been reported in the phosphors having two luminescent centers such as, $\mathrm{Pr}^{3+}-\mathrm{Yb}^{3+}$ [15], $\mathrm{Nd}^{3+}-$ $\mathrm{Yb}^{3+}[16], \mathrm{Er}^{3+}-\mathrm{Yb}^{3+}[17], \mathrm{Ho}^{3+}-\mathrm{Yb}^{3+}$ [18], and $\mathrm{Dy}^{3+}-$ $\mathrm{Yb}^{3+}$ [19] co-doped systems. Research on NIR quantum cutting phosphors has shown experimental evidence of generation of two NIR photons from the phosphors with $\mathrm{Tm}^{3+}-\mathrm{Yb}^{3+}[20], \mathrm{Er}^{3+}-\mathrm{Yb}^{3+}[21]$ and $\mathrm{Ho}^{3+}-\mathrm{Yb}^{3+}$ co-doping [22,23].

Fig. $2 \mathrm{~b} \sim \mathrm{d}$ shows quantum cutting mechanisms which are based on the resonance electron transfer between two optical centers located in close proximity. The ET can be described as a first-order rate process, governed by the degree of overlap between the donor emission and the acceptor absorption. Energy splitting is plausible by population of an intermediate energy level of the donor. In contrast, if there is no spectral overlap, a second-order cooperative sensitization may dominate the relaxation process, resulting in simultaneous excitation of two acceptors and subsequent emission of two NIR photons (Fig. 2e). For efficient cooperative sensitization to be

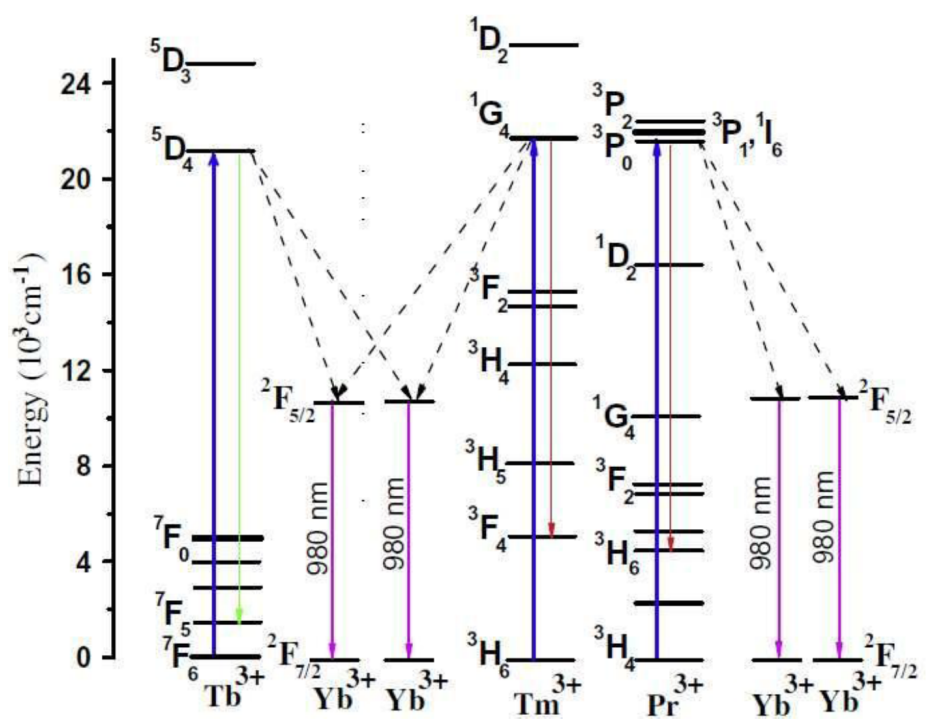

Figure 3. Schematic energy level diagrams of $\mathrm{GdAl}_{3}\left(\mathrm{BO}_{3}\right)_{4}: \mathrm{Pr}, \mathrm{Yb}, \mathrm{GdAl}_{3}\left(\mathrm{BO}_{3}\right)_{4}: \mathrm{Tb}, \mathrm{Yb}$, and $\mathrm{GdAl}_{3}\left(\mathrm{BO}_{3}\right)_{4}: \mathrm{Tm}, \mathrm{Yb}$ showing the concept of NIR QC with visible excitation at 489,485 , and $475 \mathrm{~nm}$, respectively, as copied form ref. [26]. 
observed, the sum of the energy of the absorption transitions of the two acceptors must equal the energy of the donor emission [24,25].

Fig. 3 shows part of the energy level diagram of $\mathrm{RE}^{3+}(\mathrm{RE}=\mathrm{Pr}$, Tb and $\mathrm{Tm})$ and $\mathrm{Yb}^{3+}$ in $\mathrm{GdAl}_{3}\left(\mathrm{BO}_{3}\right)_{4}$. The electronic transition of $\mathrm{Pr}^{3+}$ at an energy level ${ }^{3} \mathrm{P}_{0}$ $\rightarrow{ }^{3} \mathrm{H}_{4}$ possesses nearly twice energy than the transition of $\mathrm{Yb}^{3+}$ at ${ }^{2} \mathrm{~F}_{5 / 2} \longrightarrow{ }^{2} \mathrm{~F}_{7 / 2}$ transition. Also $\mathrm{Yb}^{3+}$ has no other energy levels up to the UV region for any further electronic transitions. This makes the co-operative sensitization process as a dominant process in the system. The concept of NIR QC through a co-operative electron transfer from the $\mathrm{GdAl}_{3}\left(\mathrm{BO}_{3}\right)_{4}: \mathrm{RE}^{3+}$, $\mathrm{Yb}^{3+}(\mathrm{RE}=\mathrm{Pr}, \mathrm{Tb}$ and $\mathrm{Tm})$ is also represented in Fig. 3. The mechanism of NIR QC can be observed in the above system through $\mathrm{Pr}^{3+}$ ion from the excitation of ${ }^{3} \mathrm{P}_{0}$ energy level. Down-conversion of excited ions of $\mathrm{Pr}^{3+}$ occurs through energy transfer to two $\mathrm{Yb}^{3+}$ ions via electronic transition of ${ }^{3} \mathrm{P}_{0} \rightarrow{ }^{2} \mathrm{~F}_{5 / 2}+{ }^{2} \mathrm{~F}_{5 / 2}$. The combination of one $\mathrm{Tb}^{3+}$ and two $\mathrm{Yb}^{3+}$ ions has also been studied. Upon excitation with blue light $\left(\mathrm{Tb}^{3+}:{ }^{7} \mathrm{~F}_{6} \rightarrow{ }^{5} \mathrm{D}_{4}\right.$ transition $), \mathrm{GdAl}_{3}\left(\mathrm{BO}_{3}\right)_{4}: \mathrm{Tb}, \mathrm{Yb}$ may display a co-operative energy transfer from $\mathrm{Tb}^{3+}$ to two $\mathrm{Yb}^{3+}$ ions via ${ }^{5} \mathrm{D}_{4} \rightarrow{ }^{2} \mathrm{~F}_{5 / 2}+{ }^{2} \mathrm{~F}_{5 / 2}[24,27]$.

\section{Criteria for the Choice of Host Crystal}

When the electron from $4 \mathrm{f}$ energy level excited into $5 \mathrm{~d}$ orbital and extends beyond next energy levels such as $5 \mathrm{~s}$ and $5 \mathrm{p}$, the spectroscopic properties of rare earth dopants in an electronic configuration such as $4 \mathrm{f}^{N-1} 5 \mathrm{~d}$ are strongly influenced by lattice of the host crystal. Due to this influence, the electronic transition between $4 \mathrm{f}^{N}$ and $4 \mathrm{f}^{N-1} 5 \mathrm{~d}$ states due to absorption or emission of photons will be significantly different from the electronic transitions within the $4 \mathrm{f}^{N}$ configuration. As the inter-configuration $4 \mathrm{f}^{N}-$ $4 \mathrm{f}^{N-1} 5 \mathrm{~d}$ transitions of the lanthanide ions are parity-allowed; they have intensities up to 10000 times stronger than the strongest $4 \mathrm{f}^{N}-4 \mathrm{f}^{N}$ transitions [28].

The choice of host materials is of great importance in designing lanthanide-based luminescent materials for efficient photovoltaic applications. For the enhancement of the photovoltaic efficiency the host lattice must go through certain criteria such as the lattice of host material should be close enough and match well with the lattice of dopant ions and should also possess lower phonon energy. In a host crystal, atoms are not fixed at particular rigid sites on a lattice but they are continuously vibrating in periodic structure in the form of a wave. Phonons are the quantum of lattice vibrational energy and their behavior determines various properties of solids such as specific heat, thermal conductivity, etc. Although the energy level structures of most of the lanthanide ions is independent of the host material, the phonon energy plays an important role in controlling the non-radiative transitions occurring due to multiphonon relaxation between closely placed energy levels.

Host crystals with perfect lattice arrangement possess lower phonon energy, which decreases probability of non-radiative radiations resulting in higher luminescence efficiency. The maximum phonon energies of different inorganic host materials are summarized in the following: iodide $\left(160 \mathrm{~cm}^{-1}\right)<$ bromide (175 $\left.190 \mathrm{~cm}^{-1}\right)<$ chalcogenide $\left(200 \sim 300 \mathrm{~cm}^{-1}\right)<$ fluoride $\left(500 \sim 600 \mathrm{~cm}^{-1}\right)<$ telluride $\quad\left(600 \sim 850 \mathrm{~cm}^{-1}\right)$ $<$ germinate $\left(800 \sim 975 \mathrm{~cm}^{-1}\right)<$ silicate $(1,000 \sim 1,100$ $\left.\mathrm{cm}^{-1}\right)<$ phosphate $\left(1,100 \mathrm{~cm}^{-1}\right)<$ borate $\left(1,400 \mathrm{~cm}^{-1}\right)$ [29]. Lower phonon energy, high refractive index and better thermal stability makes fluoride based hosts a promising phosphor host for up-conversion and quantum cutting luminescence [7,30,31]. The efficiency of visible quantum cutting or NIR quantum cutting is strongly dependent on the dopant ion- host crystal interactions. The research on visible quantum cutting shows that in order to observe better quantum cutting efficiency, the $4 f 5 \mathrm{~d}$ states of the dopant 
must have a higher energy than the ${ }^{1} \mathrm{~S}_{0}$ state. However, it is difficult to calculate the position of $4 f 5 \mathrm{~d}$ levels because the properties of the mixed $4 f 5 \mathrm{~d}$ configuration depend on the various electron interactions including contributions of crystal field splitting, as well as the effect of covalency, chemical binding, ligand polarization and anisotropy of the luminescent center [32]. E. van der Kolk et al. stated that to obtain high energy $4 f 5 \mathrm{~d}$ states, two important conditions need to be fulfilled: (i) a high centroid energy, namely a small centroid shift, and (ii) a small crystal field splitting [32-34]. The first condition of high centroid energy relates with a high electronegativity of the anions [32]. The fluoride ion, due to their higher electronegativity, are the most preferred in this case and also the centroid shift tends to increase in a manner from fluoride compounds to the sulfate, carbonate, phosphate, borate, silicate and aluminate compounds, respectively [33].

There are number of factors relating to host crystal which are responsible for variation in electronic transition and energy transfer. Crystal structure is one of the important factors responsible for the efficiency of quantum cutting. The relation between size and shape of the coordination polyhedron and the energy of the $5 \mathrm{~d}$ crystal field states of trivalent $\mathrm{RE}$ ions were discussed by Dorenbos et al. [35,36]. The structures with cuboctahedra, five-capped and tri-capped trigonal prism coordination always try to create smaller crystal field as compared to cubal and octahedral type coordination where crystal field splitting is $2 \sim 3$ times larger. Thus the one which produces smaller crystal field splitting are more favorable for efficient quantum cutting phenomenon. Along with coordination, a small radius and high charge of a second cation presented in the host crystals also help to enhance quantum efficiency. For example, high QC has been observed in $\mathrm{LaZrF}_{7}: \mathrm{Pr}^{3+}$ with small and high charged $\mathrm{Zr}^{4+}$ ions [36]. This observation was explained by the nephelauxetic effect [37]. The second cation interacts strongly with the nearest neighbor $\mathrm{Pr}^{3+}$ ion and then gives rise to a small centroid shift which leads to high $\mathrm{QC}$.

\section{Factors Affecting Quantum Cutting Efficiency}

\section{Size dependent properties}

Fig. 4 shows comparison of the band gap energy of a bulk semiconductor, a quantum dot and an atom. The reduction in size due to the loss of energy states results into increase in band gap energy, which results into the blue shift of the photoluminescence and photo-absorbance spectra. The effect was reported in

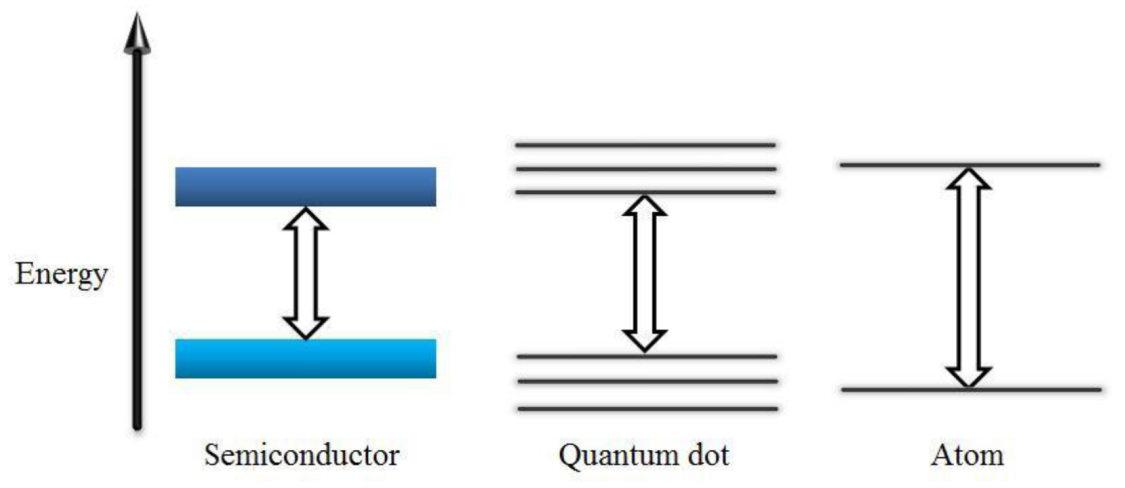

Figure 4. The comparison of band gap energy of a bulk semiconductor, a quantum dot and in an atom. Due to shrinkage in size, more energy states has been lost which results in increase in band gap energy. 
semiconductor materials such as $\mathrm{ZnO}$ nanoparticle where the emission shows blue shift when compared to its bulk counterpart [38]. Schmechel et al. observed blue shift effect in nanocrystalline $\mathrm{Y}_{2} \mathrm{O}_{3}: \mathrm{Eu}^{3+}$ samples [39]. The size dependent shift takes place in the excitonic band. With reduction in particle size, the energy level of the conduction band increases with broadening of the forbidden band making the energy transfer process shifting towards blue region. According to Prasad et al. nanostructure control provides following advantages [40]:

- Controlling the particle size, tuning of energy level structure including relative ordering and spacing of energy levels can be possible by manipulation of the crystal field surrounding the ions. This phenomenon is useful in photon cascade emission.

- Selection of lattice with lower phonon frequency and density of phonon states to minimize competing non-radiative multiphonon relaxation processes. For this reason, the work on quantum cutters has focused on the use of hosts such as fluorides, aluminates, and borates with smaller maximum phonon frequencies $(\sim$
$500 \mathrm{~cm}^{-1}$ ) compared to many oxides such as silica (maximum phonon frequencies $>1000 \mathrm{~cm}^{-1}$ ). Nanocrystal environments with discrete and controllable phonon spectrum may provide some advantages.

- The ion pairs involve multipolar and/or exchange interactions that are strongly dependent on the ion-pair separation. Nanostructure control provides an opportunity to optimize the ion-pair interaction.

\section{Effect of temperature}

Temperature has major impact on the quantum cutting process of various dopant systems. The temperature dependence of the $\mathrm{Gd}-\mathrm{Eu}$ quantum-cutting system is worth studying [6]. Due to a mismatch in energy, energy transfer by cross relaxation is expected to be inefficient at low temperatures and changes in the visible spectra as a function of temperature have been observed.

The dependence of emission intensity of $\mathrm{Yb}^{3+}$ at 998 $\mathrm{nm}$ on temperature was explained in Fig. 5 [41]. Higher temperature leads to increased number of

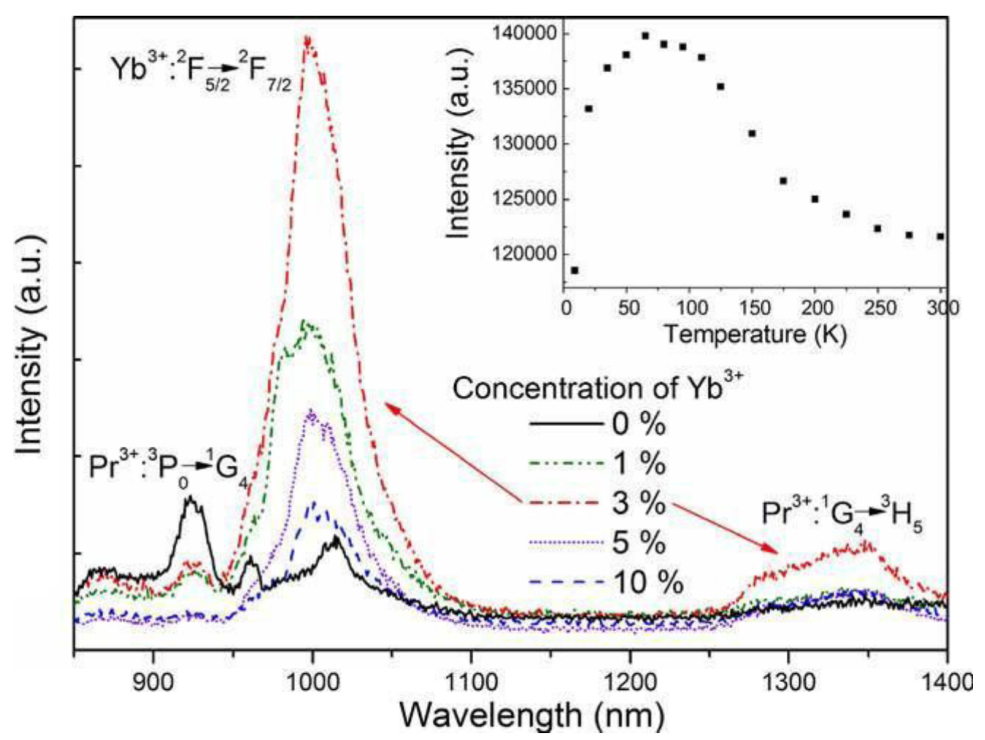

Figure 5. Infrared emission spectra of the samples with different $\mathrm{Yb}^{3+}$ concentration under $442 \mathrm{~nm}$ excitation at $300 \mathrm{~K}$. Inset shows the infrared emission $\left(998 \mathrm{~nm}\right.$ ) intensity of $\mathrm{Yb}^{3+}$ under $442 \mathrm{~nm}$ excitation for various temperature in $0.5 \% \mathrm{Pr}^{3+} / 3 \% \mathrm{Yb}^{3+}$ co-doped samples, as copied form ref. [41]. 
available phonons and phonon assisted energy transfer rate. Due to the increase in energy transfer rate, the level mismatch does not obstruct the energy transfer which can be observed from the coincident increase of $\mathrm{Yb}^{3+}$ NIR emission intensity. At higher temperature, the $\mathrm{Yb}^{3+}$ emission intensity decreases due to the efficient energy transfer from $\mathrm{Yb}^{3+}$ to $\mathrm{Pr}^{3+}$. In a co-operative energy transfer process, the $\mathrm{Yb}^{3+}$ NIR emission intensity almost remains constant with increasing temperature [41].

\section{Concentration quenching}

The rate of energy transfer in quantum cutting phosphor is highly dependent upon concentration of dopant in the system. In $\mathrm{QC}$ phosphor having $\mathrm{RE}-\mathrm{Yb}$ combination, the rate of NIR quantum cutting increases up to threshold concentration of $\mathrm{Yb}^{3+}$ and further increase will reduce the efficient energy due to increase in cross relaxation rate of $\mathrm{Yb}^{3+}$ ions.

From the Fig. 6, it was observed that up to certain

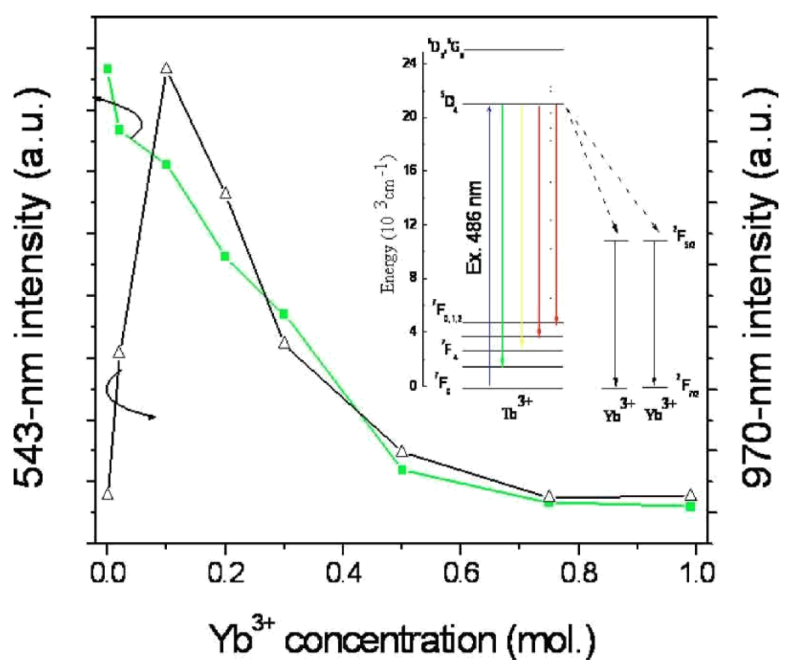

Figure 6. Dependence of the green- and NIR-emission intensities on the $\mathrm{Yb}^{3+}$ doping concentration in $\mathrm{GdBO}_{3}: \mathrm{Tb}^{3+}, \mathrm{Yb}^{3+}$ nano-phosphors. Inset shows schematic energy levels of the nano-phosphors showing possible mechanisms for a NIR QC under excitation of visible with $\lambda_{\mathrm{ex}}=486 \mathrm{~nm}$, as copied form ref. [42]. concentration of $\mathrm{Tb}^{3+}$ the energy transfer to $\mathrm{Yb}^{3+}$ was found effective which can be reflected from the enhancement of emission intensity at $970 \mathrm{~nm}$. However at higher $\mathrm{Yb}^{3+}$ concentration, cross relaxation takes place between $\mathrm{Yb}^{3+}$ ions which effectively reduces the luminescence yield. The reduction in NIR emission at $970 \mathrm{~nm}$ with increase in $\mathrm{Yb}^{3+}$ concentration is due to concentration quenching effect. The amount of dopant $\mathrm{Yb}^{3+}$ is rarely affected due to cross relaxation process than other $\mathrm{RE}$ ions so higher amount of $\mathrm{Yb}^{3+}$ can be incorporated into host crystal.

\section{Synthesis Techniques for Quantum Cutting Phosphors}

\section{Solid state method}

Solid state method is a conventional synthesis process for various quantum cutting materials. One of the most important advantages over other processes is the simplicity which can be applied for industrial purpose [43]. Various phosphor host materials have been synthesized by this process such as yttrium aluminum garnets (YAG) [43], $\mathrm{YNbO}_{4}$ [44], $\mathrm{YVO}_{4}$ [45], $\mathrm{CeO}_{2}$ [46], $\mathrm{Y}_{2} \mathrm{O}_{3}$ [47], $\mathrm{Y}_{2} \mathrm{SiO}_{5}$ [48], $\mathrm{CaWO}_{4}$ [49], $\mathrm{YBO}_{3}$ [50], $\mathrm{BaGdB}_{9} \mathrm{O}_{16}$ [51], and $\mathrm{LiTeO}_{4}$ [52]. Starting materials, usually metal oxides, are mixed together in accordance to stoichiometry of the final product. Subsequently, these mixtures were calcinated at higher temperature e.g., $650^{\circ} \mathrm{C}[52] \sim 1850^{\circ} \mathrm{C}$ [47]. Although this process seems quite simple, the product's morphology is poor because the agglomerated particles with irregular shapes are always obtained. To overcome this problem, using fluxes such as $\mathrm{PbO}, \mathrm{PbF}_{2}, \mathrm{BaO}, \mathrm{BaF}_{2}, \mathrm{BCl}_{2}, \mathrm{SrF}_{2}, \mathrm{YF}_{3}$ and $\mathrm{AlF}_{3}$ can improve the morphology of products and limit the crystal growth. [43,53]. Recently, Sun et al. (2013) reported the quantum-cutting $\mathrm{CaWO}_{4}: \mathrm{Nd}^{3+}$, $\mathrm{Yb}^{3+}$ synthesis using solid state route. Starting mate- 
rials $\left(\mathrm{CaCO}_{3}, \mathrm{WO}_{3}, \mathrm{Nd}_{2} \mathrm{O}_{3}\right.$, and $\left.\mathrm{Yb}_{2} \mathrm{O}_{3}\right)$ were mixed in an agate mortar and then, two-step heat treatment at $300^{\circ} \mathrm{C}$ for $2 \mathrm{~h}$ and $900^{\circ} \mathrm{C}$ for $3 \mathrm{~h}$ was carried out. The as-prepared well-crystalline material match perfectly to the body-center tetragonal phase of $\mathrm{CaWO}_{4}$. The optimized doping concentration in $\mathrm{CaWO}_{4}$ host was $1 \% \mathrm{Nd}^{3+}-10 \% \mathrm{Yb}^{3+}$, and maximum quantum efficiency obtained was around 164.03\%. However, the discussion on particle's morphology was not presented in this report [49].

\section{Combustion method}

Combustion is one of the potential processes for material synthesis using self-propagating high temperature from exothermic reactions between metal nitrates and organic fuels such as urea, carbohydrazide, glycine etc. This method has been reported as an effective and low-cost process since it requires low temperature and short time [54]. There are many reports have been published recently on phosphor synthesis by combustion method in various host such as $\mathrm{Y}_{2} \mathrm{O}_{3}$ [55], $\mathrm{GdBO}_{3}$ [42], $\mathrm{GdAl}_{3}\left(\mathrm{BO}_{3}\right)_{4}$ [26,56], $\mathrm{GdO}_{3}$ [57], $\mathrm{BaMgAl}_{10} \mathrm{O}_{17}$ [58], yttrium silicate [59], $\mathrm{LaSrAl}_{3} \mathrm{O}_{7}$ [60], $\mathrm{Ca}_{2} \mathrm{~V}_{2} \mathrm{O}_{7}$ [61] and YAG [62]. Aruna et al. (2008) discussed in detail that combustion method is categorized into three types: conventional combustion synthesis (starting materials are in solid state), solution-combustion synthesis (starting materials are in aqueous solution) and flame combustion synthesis (gas-phase combustion) [54]. Solution-combustion synthesis produces smaller and more homogeneous particles than those produced by solid-combustion because reactions take place from homogeneous solutions. Solution-combustion has been recommended to synthesize rare-earth doped materials because small amount of rare-earth dopant can be uniformly mixed with host materials. The synthesis process is simple. Starting material (mixture of oxidizers and fuels) is placed in pre-heated furnace at $500^{\circ} \mathrm{C}$. After few minutes, auto-ignition happens for several seconds. After completion of combustion, powder is collected and processed for post heat treatment [55]. Although combustion synthesis can be carried out easily within short time, the high temperature produced from exothermic reactions can deteriorate particle's morphology by agglomeration and pore formation due to release of various gaseous products [58]. In order to produce nano-sized particles through combustion synthesis, other processes such as milling and salt assisting are used [53,54]. Through combustion route, Zhang et al. (2010) could synthesize YAG co-doped RE-Yb (Tb, Tm, Pr) which exhibited excellent crystalline of pure YAG at low temperature of post heat treatment $\left(900^{\circ} \mathrm{C}\right.$ for 10 hrs). They produced fine homogeneous particles which have excellent optical properties, and quantum efficiency closed to 200\% (191\% for $\mathrm{Tb}^{3+} / \mathrm{Yb}^{3+}, 165 \%$ for $\mathrm{Tm}^{3+} / \mathrm{Yb}^{3+}$ and $173 \%$ for $\mathrm{Pr}^{3+} / \mathrm{Yb}^{3+}$ ) [62].

\section{Precipitation method}

Since particle's morphology and size have significant effects on optical properties of the luminescent materials, recent research on synthesis processes which allow controlling particle's morphology and size becomes more attractive for many researchers [63]. As being discussed above, agglomeration resulted in big particles and unsatisfied morphology always happens in conventional solid state method and combustion. Co-precipitation is a promising method that enables to produce highly homogeneous products due to good mixing of starting materials, and reactions happen at lower temperature; usually room temperature [64]. Especially, through co-precipitation method, particle size and morphology can be controlled that allow producing desirable products [65]. Many phosphor hosts have been successfully synthesized using this process such as $\mathrm{YF}_{3}$ [17], $\mathrm{Y}_{2} \mathrm{O}_{3}$ [66], $\mathrm{BaAl}_{2} \mathrm{O}_{4}$ [67], $\mathrm{YVO}_{4}$ [63], $\mathrm{CaSb}_{2} \mathrm{O}_{6}$ [67], 
$\mathrm{BaMoO}_{4}$ [68], YAG [69-71], $\mathrm{BaMgAl}_{10} \mathrm{O}_{17}$ [72], $\mathrm{CaWO}_{4}$ [73], $\mathrm{YPO}_{4}$ [74], $\mathrm{Lu}_{2} \mathrm{O}_{3}$ [75], $\mathrm{LaVO}_{4}, \mathrm{GdVO}_{4}$ [76] etc. Comparing to previous conventional solid state and combustion method, co-precipitation method is more complicated, and it requires careful control of reaction parameters. General process is carried out through three important steps: (1) precursor solution preparation, (2) precipitation and (3) crystallization. For precursor solution preparation, various kinds of metal-contained materials have been used as starting materials such as metal oxides [17,66], metal chlorites [67], metal nitrates [64,68,70,71] and metal acetates [77]. Those starting materials are stoichiometrically dissolved respective solvents such as water or ethanol. Precipitation reaction is the most important step that requires careful control. This step starts with addition of precipitating agents such as $\mathrm{NH}_{4} \mathrm{HCO}_{3}$ [17], $\mathrm{NH}_{4} \mathrm{OH}$ [63], $\mathrm{NaOH}$ [67] and urea [68]; and mixing/stirring at particular temperature. Here, heating temperature, reaction time, mixing level (stirring) and $\mathrm{pH}$ control are important parameters that determine the final product's morphology and size [63]. After reaction, precipitates are collected, washed and dried. Finally, dried precipitates were processed for high temperature heat treatment for desirable crystalline nanostructures. Rambabu et al. (2013) reported their work on synthesis of down-conversion phosphor, $\mathrm{YVO}_{4}: \mathrm{Bi}^{3+} / \mathrm{Yb}^{3+}$ under assisting of ethylene glycol as surfactant [63]. They found that $\mathrm{pH}$ is one of the main factors determining the final products' morphology and size since $\mathrm{pH}$ affect the nucleation and growth rate of the particles during co-precipitation. However, $\mathrm{pH}$ doesn't affect the crystal phase of products. They observed that at lower $\mathrm{pH}$ ( $\mathrm{pH}$ 6), $\mathrm{YVO}_{4}$ particles seem irregular shape and bigger size $(3 \sim 6 \mu \mathrm{m})$. However, at higher $\mathrm{pH}(\mathrm{pH} 710)$ particle's morphology shows regular sharp and smaller particle's size $(500 \sim 600 \mathrm{~nm}$ for $\mathrm{pH} \mathrm{9)}$, and at $\mathrm{pH} \mathrm{9}$, optical properties of particles were also enhanced [63].

\section{Hydrothermal method}

Shape, dimensionality and size of luminesce materials are much attractive for the modern materials architectures because those parameters affect the optical properties of the final products [76]. Therefore, the exploring of new controllable methods for producing good products is still in a challenging progress. Hydrothermal synthesis has been reported as one of the best options for producing nanomaterials since it takes place in lower temperature, homogeneous nucleation and proceeds well-defined morphologies [78]. Furthermore, in this process it is easy to control the reaction conditions and scale up with high yield for a commercial purpose [77]. Based on recent reports, there are various kinds of particle's shapes have been produced by hydrothermal synthesis such as spindle-like, disk, octahedral [76], sphere [78], one-dimensional structures (noodle-like [77], nano-rode/nano-wire [79,80], hexagonal and square [81]. Using hydrothermal method, a wide range of host materials can be synthesized such as $\mathrm{LaF}_{3}, \mathrm{LuF}_{3}$ [76], $\mathrm{NaGd}\left(\mathrm{MoO}_{4}\right)_{2}$ [78], $\mathrm{BaAl}_{2} \mathrm{O}_{4}$ [77], $\mathrm{NaYF}_{4}$ [18, 79-81], $\mathrm{LuBO}_{3}$ [82], $\mathrm{YF}_{3}, \mathrm{GdF}_{3}$, and $\mathrm{YbF}_{3}$ [83]. The process of hydrothermal synthesis is quite similar to precipitation process, however it is more advanced since its reaction happens in closed system at temperature higher than $100^{\circ} \mathrm{C}$ and pressure is higher than 1atm. The first step is precursor solution preparation. Precursor solution can be nitrate-based aqueous solution or chlorite-based aqueous solution. Metal oxides are used as starting materials which are stoichiometrically dissolved in $\mathrm{HNO}_{3}$ (nitrate-based) [77-80] or in $\mathrm{HCl}$ (chlorite-based) [76,79] at heating condition. Then, stirring has to be processed until it becomes a homogenous solution. The second step is reaction. Nitrate-based solution or chlorite-based solution can be diluted in water and precipitation agents such as $\mathrm{NH}_{3}, \mathrm{HCl}$ (acidic condition) [76,80] or $\mathrm{NaOH}$ (basic condition) [79] followed by stirring. 
Then, the precipitates are placed into Teflon-lined autoclave at temperature higher than $100^{\circ} \mathrm{C}$ for a period of time. Finally, precipitates are separated by centrifuging or filtering followed by washing and drying. Chen et al. (2009) reported synthesis of $\mathrm{NaYF}_{4}: \mathrm{Pr}^{3+}, \mathrm{Yb}^{3+}$ quantum-cutting phosphor using hydrothermal process with an excellent record [80]. They found that as-synthesized products (drying at $70^{\circ} \mathrm{C}$ for $8 \mathrm{hrs}$ ) exhibited high crystalline with pure hexagonal $\mathrm{NaYF}_{4}$. The products were hexagonal prismatic micro-rods with high uniformity and smooth surfaces. The maximum quantum efficiency obtained was $181.6 \%$ which is close to $200 \%$.

\section{Sol-gel method}

Sol-gel technique is a wet chemical process which is capable to produce homogeneous and controllable-sized particles with high purity of chemical composition at lower temperature [84]. Based on the rheological properties of sols, various sharps of final products can be formed by depositing on subtracts to form thin films through dip-coating or spin coating, casting into a desirable sharp (monolithic, fiber...) and grinding to yield powder. There were many host materials have been synthesized by sol-gel such as $\mathrm{Y}_{2} \mathrm{ZrO}_{7}$ [84], $\mathrm{LiGdF}_{4}$ [85], $\mathrm{CaMoO}_{4}$ [86], $\mathrm{YVO}_{4}$ [87], $\mathrm{ZrO}_{2}-\mathrm{B}_{2} \mathrm{O}_{3}$ [88], YAG [89,90] etc. Alternatively, so-gel can be combined with other processes such as Pechni and combustion process to optimize the quality of desired products. In general, sol-gel process can be a colloid route and metal-organic route. For colloid route, metal nitrates or chlorites can be used as starting materials dissolved in aqueous solution, and a single chelating agent (e.g. malic acid, citric acid) or a complex chelating agent (e.g. malic acid with polyethylene glycol or citric acid with ethylene glycol) are added [86-90]. pH of the solutions has to be controlled at acidic condition. For metal-organic route metal alkoxides are used as starting materials dissolved alcoholic solution in water condition [88]. After gelation, water content has to be removed form gels by drying, and finally, thermal treatment is used for crystallization. Zhou et al. (2010) synthesized YAG: $\mathrm{Ce}^{3+}-\mathrm{Er}^{3+}$ down-conversion phosphor by sol-gel process using citric acid and ethylene glycol as chelating agents [90]. They successfully obtained pure phase of YAG after crystallization with homogeneous size and morphology of the particles. They found that energy from broadband visible light of $\mathrm{Ce}^{3+}$ emission can transfer effectively to NIR of $\mathrm{Er}^{3+}$ at $1.5 \mu \mathrm{m}$ with maximum rate of $86.7 \%$.

\section{Thin film methods}

Quantum-cutting thin film phosphors are generally fabricated by pulse laser deposition (PLD) process by using silicon substrate and metal-oxide targets in oxygen condition at high temperature $\left(650^{\circ} \mathrm{C}\right)$ followed by post thermal treatment [91-93]. Che et al. (2012) successfully fabricated near-infrared quantum cutting $\mathrm{YVO}_{4}: \mathrm{Yb}^{3+}$ thin-film using PLD process. They found that without post heat treatment $\mathrm{YVO}_{4}: \mathrm{Yb}^{3+}$ film was amorphous, however after thermal treating at $1,000^{\circ} \mathrm{C}$ for $1 \mathrm{~h}$, pure tetragonal phase of $\mathrm{YVO}_{4}$ was observed. $\mathrm{YVO}_{4}: \mathrm{Yb}^{3+}$ showed high transparency (90\%) and with maximum quantum efficiency was $127.7 \%$ [91]. Qu et al. (2012) also used PLD method to fabricate $\mathrm{Y}_{2} \mathrm{O}_{3}: \mathrm{Bi}^{3+}-\mathrm{Yb}^{3+}$ thin film using a $\mathrm{KrF}$ excimer laser at $248 \mathrm{~nm}, 650^{\circ} \mathrm{C}$ in $\mathrm{O}_{2}$ condition $\left(8 \times 10^{-4} \mathrm{~Pa}\right)$ with post heat treatment at $1200^{\circ} \mathrm{C}$ for $2 \mathrm{~h}$. They studied on the effect of film's thickness on the luminescent properties of $\mathrm{Y}_{2} \mathrm{O}_{3}: \mathrm{Bi}^{3+}, \mathrm{Yb}^{2+}$. Increasing the thickness of the film from $0.31 \mu \mathrm{m}$ to $5.49 \mu \mathrm{m}$ leads to increase the grain size of $\mathrm{Y}_{2} \mathrm{O}_{3}$ from 13 to $48 \mathrm{~nm}$, respectively. They observed that $\mathrm{PL}$ emission increased monotonically as the film thickness increased due to good crystallinity, and the maximum quantum efficiency was 152\% [92]. Furthermore, Qu et al. (2012) also observed the effect of oxygen pressure on 
the film's quality [93]. They found an interesting result that $\mathrm{O}_{2}$ pressure in PLD process had significant effects on particle's morphology, size and the orientation of particles on the substrate. At lower $\mathrm{O}_{2}$ pressure $(0.2 \mathrm{~Pa})$, the film was smooth surface, grain size and grain boundary were undetermined. Increasing the $\mathrm{O}_{2}$ pressure to $1 \mathrm{~Pa}$, gain size was bigger and grain boundary was clearly observed. Further increase to $5 \mathrm{~Pa}$, uniform pyramid structure of the grain was observed; and this structure collapsed when $\mathrm{O}_{2}$ pressure increased more to $10 \mathrm{~Pa}$. They also claimed that at lower $\mathrm{O}_{2}$ pressure $(0.2 \sim 3 \mathrm{~Pa})$ the orientation of $\mathrm{Y}_{2} \mathrm{O}_{3}$ on $\mathrm{Si}$ (100) substrate preferred as (222), while higher $\mathrm{O}_{2}$ pressure (400) was dominant. This is due to the surface energy required for (222) orientation is lower than that of (400) [93].

\section{Melting-quenching method}

Melting-quenching process is generally used to fabricate glass ceramic phosphors such as oxy-fluoride glasses [94-96], borate glasses [97,98], borosilicate glasses [99], phosphate glasses [100], germanate glasses [101], silicate glasses [102] etc. The process is quite simple, but it needs high temperature for melting materials. The starting materials, high purity products such as metal oxides or metal carbonates, are homogeneously mixed together by an agate mortar and pestle [95]. Then, this mixture is melted at higher temperature from $1000^{\circ} \mathrm{C}$ for borate glasses [98] to $1600^{\circ} \mathrm{C}$ for germinate glasses [101]. The melting samples are poured into a plate, and kept for cooling. Finally, glass ceramics are polished to obtain the desired thicknesses. In some cases, annealing at $300 \sim 400^{\circ} \mathrm{C}$ was carried out after polishing [95,98]. Bo et al. (2013) has been synthesized down-conversion glass phosphor using phosphate glasses $\left(50 \mathrm{P}_{2} \mathrm{O}_{5}-45 \mathrm{BaO}-5 \mathrm{Al}_{2} \mathrm{O}_{3}\right)$ with $\mathrm{Tm}^{3+}$ and $\mathrm{Yb}^{3+}$ as dopants, melting at $1350^{\circ} \mathrm{C}$ for $30 \mathrm{~min}$ [100]. Based on the Inokuti - Hiryama's model, they could prove the en- ergy transfer from $\mathrm{Tm}^{3+}$ to $\mathrm{Yb}^{3+}$ at the maximum energy transfer efficiency of $69.8 \%$, while maximum quantum efficiency was 169.8\%. Zhou et al. (2012) also successfully fabricated the quantum-cutting glass phosphors using oxy-fluoride glasses $\left(60 \mathrm{SiO}_{2}-\right.$ $20 \mathrm{Al}_{2} \mathrm{O}_{3}-20 \mathrm{CF}_{2}: \mathrm{Pr}^{3+}, \mathrm{Yb}^{3+}$ ) melting at $1400^{\circ} \mathrm{C}$ for 30 min. They found that the maximum quantum efficiency was $158 \%$ at $0.1 \mathrm{~mol} \mathrm{Pr}$ and $1 \mathrm{~mol} \mathrm{Yb}$. However, covering the rare-earth doped glasses on the $\mathrm{c}-\mathrm{Si}$ solar cell showed negative effect due to the deviation between the real quantum efficiency and the theoretical value of the glass sample and the scattering of the emitting light [94].

\section{Down-shifting Materials}

Down-shifting materials are used in photovoltaics mainly for overcoming the poor spectral response to shorter wavelength light. Down-shifting material helps to enhance external quantum efficiency of PV by emitting in the suitable wavelength range. The absorption of high energy photon by down-shifting materials can results in generation of single electron - hole pair in the solar cell. The down-shifting material is used as a solar concentrator as well as solar energy conversion to longer wavelength.

Rowan et al. [103] has explained few essential characteristics of ideal down-shifting materials. (i) broadband absorption, particularly in the region where the spectral response of the solar cell is low; (ii) high absorption coefficient and high luminescence quantum efficiency so that all incident light results in emission; (iii) high transmittance and narrowband emission, particularly in the region where the device response is high; (iv) large Stokes shift to minimize the self-absorption energy losses due to the spectral overlap between the absorption and emission bands; and (v) long-term stability. 


\section{Applications of Spectral Converting Materials in Photovoltaics}

The efficiency of a solar cell is limited mainly due to following factors such 1) sub-bandgap energy photon loss [104], 2) thermalization of charge carriers, 3) contact voltage loss, 4) recombination loss, 5) Junction loss and 7) reflection loss [105]. Among the factors, sub-bandgap energy loss and thermalization loss can be overcome using spectral conversion technology. A rare earth ions doped luminescent material has unique property of conversion of wavelength of absorbed light to longer or shorter wavelength. They offer the opportunity for the effective utilization of high energy and sub-bandgap energy photons that otherwise would not have been absorbed by direct bandgap absorbers.

Down-conversion and down-shifting phosphors have been used in solar cells for the reduction of thermalization losses $[27,106,107]$. The concept of down-conversion was first put forward by Dexter in 1953 [108] but the concept was experimentally supported 20 years later with $\operatorname{Pr}^{3+}$ doped $\mathrm{YF}_{3}$ phosphors [109, 110]. For the applications of down-conversion phosphors to solar cell, however, the energy level structure of $\mathrm{Yb}^{3+}$ is most well suited since it has a single excited state which corresponds to emission around $1000 \mathrm{~nm}$. The absence of other energy levels enables $\mathrm{Yb}^{3+}$ to be a good acceptor of energy transfer from other lanthanide ions. The lanthanides ions incorporated in various host crystals as a dopant material has a unique rich and well separated energy level structures as represented in Dieke energy level diagram. The doping couples like $\mathrm{Er}-\mathrm{Yb}, \mathrm{Nd}-\mathrm{Yb}$, and $\mathrm{Pr}-\mathrm{Yb}$ show a resonant two-step energy transfer process (Fig. 2d-b) and couples like $\mathrm{Tb}-\mathrm{Yb}$ and $\mathrm{Gd}-\mathrm{Yb}$ show a cooperative quantum cutting process (Fig. 2e) whereas the $\mathrm{Ce}-\mathrm{Yb}$ couple is known to undergo single step energy transfer by the metal-to-metal charge transfer (Fig. 2a).

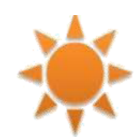

down-shifting or converion layer
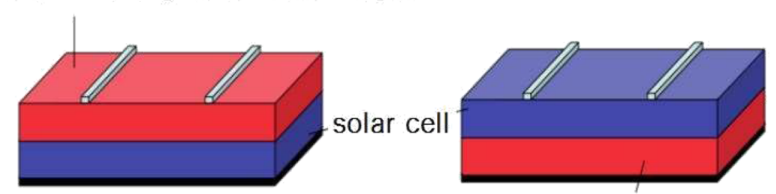

up-conversion layer

Figure 7. Application of spectral conversion layer to solar cells. Note that down-shifting or conversion layer is placed on the front side of a solar cell but up-conversion layer is placed on the rear side of a solar cell.

In order for the down-conversion materials to be incorporated in a solar cell, the materials have to be designed in a thin transparent layer on top of the solar cell (Fig. 7). To obtain the transparent layer, the phosphor powder incorporated in the layer has to be smaller than $\sim 50 \mathrm{~nm}$ in diameter, or transparent luminescent ceramic plates should be prepared. Although the potential application of down-conversion materials is centered on a solar cell, there is no reliable report demonstrating the enhancement of a solar cell by the down-conversion materials. However, there are a number of literatures reporting the enhancement by using down-shifting luminescent materials.

In 2013, Le Donne et al. reports Mn doped ZnS nanoparticles and their applications to $\mathrm{Si}$ and CIGS solar cells [111]. The particles were prepared by a wet chemical method where a solution of $\mathrm{ZnCl}_{2}$ and $\mathrm{MnCl}_{2}$ was treated with $\mathrm{Na}_{2} \mathrm{~S}$ for the precipitation of $\mathrm{Mn}$ doped ZnS particles to occur. Particles below $10 \mathrm{~nm}$ in diameter were formed and they were drop-casted on the front side of solar cells. When applied on crystalline $\mathrm{Si}-$ solar cell $\left(5 \mathrm{~cm}^{2}\right)$, external quantum efficiency (EQE) around $350 \mathrm{~nm}$ was enhanced by $6 \%$ and the short circuit current of the cell was increased by $1 \%$. On the other hand, when applied on a CIGS solar cell $\left(0.17 \mathrm{~cm}^{2}\right) \mathrm{EQE}$ around $320 \mathrm{~nm}$ was enhanced by $15 \%$ 


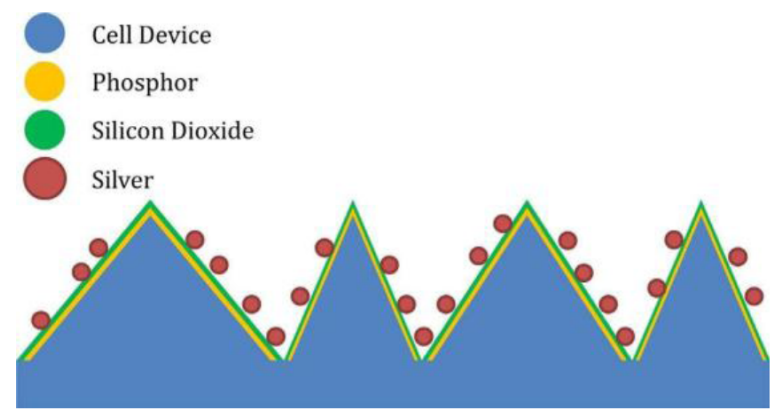

Figure 8. Schematic of textured cell structures covered with $\mathrm{Ba}_{2} \mathrm{SiO}_{4}$ :Eu nano-phosphors, $\mathrm{SiO}_{2}$ layer, and Ag NPs, as copied form ref. [112].

and the short circuit current of the cell was increased by $0.8 \%$.

Sun et al. reported in 2014 that $\mathrm{Eu}^{2+}$-doped barium silicate $\left(\mathrm{Ba}_{2} \mathrm{SiO}_{4}: \mathrm{Eu}\right)$ nano-phophors can function as a down-shifting materials for Si solar cells [112]. The nano-phosphors were spin-coated on the front side of the solar cell and coated with a metal-enhanced layer composed of $\mathrm{Ag}$ nanoparticles with a $\mathrm{SiO}_{2}$ spacer as shown in Fig. 8. The luminescence of $\mathrm{Ba}_{2} \mathrm{SiO}_{4}: \mathrm{Eu}$ nano-phosphors was proven to be enhanced by the metal-plasmonic enhancement. When applied on a $\mathrm{Si}$ solar cell, the short-circuit current was increased by $0.86 \mathrm{~mA} / \mathrm{cm}^{2}$ and the powder conversion efficiency was enhanced by $0.64 \%$.

Cattaruzza et al. introduced silicate glass slides doped with silver or copper by ion exchange in molten salts and showed their use as a coverglass for a GaAs solar cell [113]. The ion-doped glass exhibited the down-shifting properties absorbing UV and near UV light and emitting broad visible light. When the silver- and copper-doped glass was separately applied on the solar cell, the copper-doped glass showed higher output powder than the silver-doped glass. An increase by $2 \%$-output power was observed with the coper doped glass in respective to the untreated glass.

Richards et al. reported the application of a luminescent down-shifting layer on CdTe solar cells in

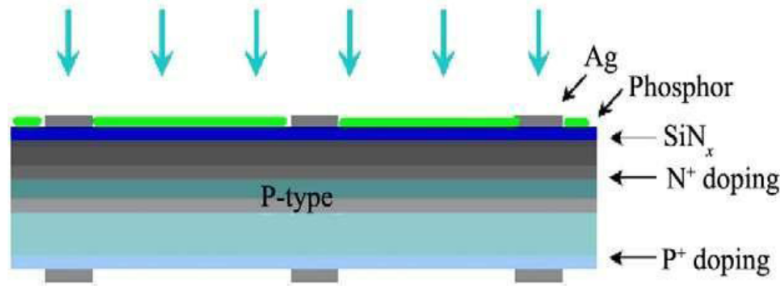

Figure 9. Device structure of down-shifting layer of $\mathrm{KCaGd}\left(\mathrm{PO}_{4}\right)_{2}: \mathrm{Eu}^{3+}$ phosphor-coated solar cells as copied form ref. [115].

2014 [29]. The down-shifting layer is composed of perylene organic dyes (BASF Lumogen $\mathrm{F}$ series) and ethylene vinyl acetate (EVA) polymer matrix. The EVA down-shifting layer is covered by a thin polymer layer of fluorinated ethylene propylene (FEP) to reduce the surface reflection. Using various dyes (from blue to orange), they obtained the relative improvement in short-circuit current as high as $9.7 \%$ in CdTe modules of $100 \mathrm{~cm}^{2}$.

In 2011, Chen et al. reported up-conversion phosphors of molybdate $\mathrm{La}_{2} \mathrm{Mo}_{2} \mathrm{O}_{9}: \mathrm{Yb}, \mathrm{R}(\mathrm{R}=\mathrm{Ho}$ or $\mathrm{Er}$ ) and their application to Si solar cells as up-conversion layer [114]. The molybdate phosphors are synthesized by a solid state method using oxide precursors and they absorb near IR light and emit visible light. The phosphors are blended with polymethylmethacrylate (PMMA) polymer to form a light conversion layer on Si solar cells. When coated on the front and rear side of the solar cell respectively, the light conversion layer enhanced the solar cell efficiency from 1.50 (front side) to $2.71 \%$ (rear side). The same group also reported the application of down-conversion phosphors to Si solar cells. They synthesized red-emitting $\mathrm{KCaGd}\left(\mathrm{PO}_{4}\right)_{2}: \mathrm{Eu}^{3+}$ phosphors by a solid state method and applied them on Si solar cell surface by blending with PMMA as illustrated in Fig. 9 [115]. The Si solar cell with phosphors showed an increase of $0.64 \%$ in cell efficiency (16.67 to 16.03\%) when compared with non-coated cell.

The examples provided above showed the efficiency 
enhancement by light-shifting (or converting) layers but there are enhancement factors provided by not only light shift or conversion but also antireflection. In order to understand how much enhancement we can achieve by this spectral conversion technology, detailed studies on separating each factor must be followed.

\section{Conclusion}

The concept of NIR quantum cutting phosphors was put forward as a down-converting material which has capability to produce two photons in visible and near IR range from each absorbed photon. NIR quantum cutting theory was applied in solar cell to enhance its efficiency by significantly reducing the energy loss due to thermalization of electron-hole pair recombination. The emission energy of NIR quantum cutting phosphors is located just above the band gap of silicon, which helps to absorb maximum amount of energy from the solar spectrum. The concept of quantum cutting through down-conversion has been put forward in 1950s using rare-earth based phosphors materials. However its practical application in solar cells still leaves much room for improvement.

The development of transparent conversion layer can become the major link for the energy conversion process. Although the efficiency of the quantum cutting phosphors has reached close to 200\%, the positive effect by the phosphors in a solar cell is still marginal. It may result from the difficulties in controlling the particle size less than $50 \mathrm{~nm}$ while keeping the quantum efficiency high and the low absorption yield due to high surface scattering. In addition, while working on quantum cutting phosphors one must consider about its compatibility as a transparent layer mounted on top of solar cells - reflective index matching with polymer matrix, sustainability within the matrix materials (organic or inorganic), long term stability and etc.

Understanding of energy transfer and down-conversion of visible and NIR quantum cutting phenomenon can be helpful for the development of new quantum cutting phosphors with higher quantum efficiency value. The combination of various oxide and fluoride hosts along with single/dual or ternary ion activation exhibit the mechanism of down-conversion, energy transfer and cross relaxation along with non-radiative relaxation in various ion pairs. Although fluoride hosts are much favored due to their wide band gap and lower phonon energy for PV application, oxide-based hosts have higher long-term stability. Therefore in the long run, oxide-based quantum cutting phosphors needs to be optimized through various synthesis processes. In addition, the development of new methods for synthesizing high efficiency phosphors will be very helpful.

The applications of quantum cutting phosphors for solar cells are still far behind from the insight given by theory. Preparation of low-cost, highly efficient having higher stability nano-phosphors with quantum cutting properties is the major challenge in front of us. However, when the use of full solar-spectrum by the quantum cutting phosphors is realized, its impact in photovoltaic market will be significant.

\section{References}

[1] A. B. Cristóbal López, A. Martí Vega, and A. Luque López, in: Springer series in optical sciences, Springer, Berlin; New York (2012).

[2] S. V. Eliseeva and J. C. G. Bunzli, Chem. Soc. Rev. 39, 189 (2010).

[3] D. Q. Chen, Y. S. Wang, and M. C. Hong, Nano Energy 1, 73 (2012).

[4] B. M. van der Ende, L. Aarts, and A. Meijerink, Phys. Chem. Chem. Phys. 11, 11081 (2009).

[5] S. Shionoya, H. Yamamoto, and W. M. Yen, 
Phosphor handbook, 2nd ed. , CRC; Taylor \& Francis distributor, London (2007).

[6] R. T. Wegh, H. Donker, K. D. Oskam, and A. Meijerink, J. Lumin. 82, 93 (1999).

[7] Q. Y. Zhang and X. Y. Huang, Progress in Mater. Sci. 55, 353 (2010).

[8] X. Y. Huang, S. Y. Han, W. Huang, and X. G. Liu, Chem. Soc. Rev. 42, 173 (2013).

[9] D. C. Yu, X. Y. Huang, S. Ye, M. Y. Peng, Q. Y. Zhang, and L. Wondraczek, Appl. Phys. Lett. 99, (2011).

[10] X. B. Chen, J. G. Wu, X. L. Xu, Y. Z. Zhang, N. Sawanobori, C. L. Zhang, Q. H. Pan, and G. J. Salamo, Optics Lett. 34, 887 (2009).

[11] M. Miritello, R. Lo Savio, P. Cardile, and F. Priolo, Phys. Rev. B 81, (2010).

[12] D. C. Yu, S. Ye, M. Y. Peng, Q. Y. Zhang, and L. Wondraczek, Appl. Phys. Lett. 100, (2012).

[13] W. J. Zhang, D. C. Yu, J. P. Zhang, Q. Qian, S. H. Xu, Z. M. Yang, and Q. Y. Zhang, Opt. Mater. Express 2, 636 (2012).

[14] D. C. Yu, X. Y. Huang, S. Ye, Q. Y. Zhang, and J. Wang, Aip Advances 1, (2011).

[15] B. M. van der Ende, L. Aarts, and A. Meijerink, Adv. Mater. 21, 3073 (2009).

[16] J. J. Eilers, D. Biner, J. T. van Wijngaarden, K. Kramer, H. U. Gudel, and A. Meijerink, Appl. Phys. Lett. 96, (2010).

[17] J. M. Meijer, L. Aarts, B. M. van der Ende, T. J. H. Vlugt, and A. Meijerink, Phys. Rev. B 81, (2010).

[18] K. M. Deng, T. Gong, L. X. Hu, X. T. Wei, Y. H. Chen, and M. Yin, Optics Express 19, 1749 (2011).

[19] Z. H. Bai, M. Fujii, T. Hasegawa, K. Imakita, M. Mizuhata, and S. Hayashi, J. Phys. D-Appl. Phys. 44, (2011).

[20] W. Zheng, H. M. Zhu, R. F. Li, D. T. Tu, Y. S. Liu, W. Q. Luo, and X. Y. Chen, Phys. Chem. Chem. Phys. 14, 6974 (2012).
[21] L. Aarts, B. M. van der Ende, and A. Meijerink, J. Appl. Phys. 106, (2009).

[22] H. Lin, D. Q. Chen, Y. L. Yu, A. P. Yang, and Y. S. Wang, Optics Lett. 36, 876 (2011).

[23] D. C. Yu, X. Y. Huang, S. Ye, and Q. Y. Zhang, J. Alloys Compd. 509, 9919 (2011).

[24] P. Vergeer, T. J. H. Vlugt, M. H. F. Kox, M. I. den Hertog, J. P. J. M. van der Eerden, and A. Meijerink, Phys. Rev. B 71, (2005).

[25] W. Strek, P. Deren, and A. Bednarkiewicz, J. Lumin. 87-9, 999 (2000).

[26] Q. Y. Zhang, G. F. Yang, and Z. H. Jiang, Appl. Phys. Lett. 91, (2007).

[27] B. S. Richards, Sol. Energ. Mat. Sol. C. 90, 1189 (2006).

[28] G. Liu and B. Jacquier, Spectroscopic Properties of Rare Earths in Optical Materials, Springer (2006).

[29] B. S. Richards, Sol. Energ. Mat. Sol. C. 90, 2329 (2006).

[30] F. Vetrone and J. A. Capobianco, Inter. J. Nanotech. 5, 1306 (2008).

[31] P. P. Fedorov, A. A. Luginina, S. V. Kuznetsov, and V. V. Osiko, J. Fluorine Chem. 132, 1012 (2011).

[32] P. A. Rodnyi, S. B. Mikhrin, P. Dorenbos, E. van der Kolk, C. W. E. van Eijk, A. P. Vink, and A. G. Avanesov, Optics Commun. 204, 237 (2002).

[33] E. van der Kolk, P. Dorenbos, A. P. Vink, R. C. Perego, C. W. E. van Eijk, and A. R. Lakshmanan, Phys. Rev. B 64, (2001).

[34] E. van der Kolk, P. Dorenbos, C. W. E. van Eijk, A. P. Vink, C. Fouassier, and F. Guillen, J. Lumin. 97, 212 (2002).

[35] P. Dorenbos, Phys. Rev. B 62, 15640 (2000).

[36] P. Dorenbos, Phys. Rev. B 62, 15650 (2000).

[37] E. van der Kolk, P. Dorenbos, and C. W. E. van Eijk, Optics Commun. 197, 317 (2001).

[38] M. W. Wang, L. D. Sun, X. F. Fu, C. S. Liao, and C. H. Yan, Solid State Commun. 115, 493 
(2000).

[39] R. Schmechel, M. Kennedy, H. von Seggern, H. Winkler, M. Kolbe, R. A. Fischer, X. M. Li, A. Benker, M. Winterer, and H. Hahn, J. Appl. Phys. 89, 1679 (2001).

[40] P. N. Prasad, Nanophotonics, Wiley, Hoboken, NJ (2004).

[41] K. Deng, X. Wei, X. Wang, Y. Chen, and M. Yin, Appl. Phys. B-Lasers and Optics 102, 555 (2011).

[42] Q. Y. Zhang, C. H. Yang, Z. H. Jiang, and X. H. Ji, Appl. Phys. Lett. 90, (2007).

[43] Z. Song, J. Liao, X. L. Ding, X. L. Liu, and Q. L. Liu, J. Crystal Growth. 365, 24 (2013).

[44] R. Zhou, Y. Kou, X. Wei, C. Duan, Y. Chen, and M. Yin, Appl. Phys. B-Lasers and Optics 107, 483 (2012).

[45] G. C. Jiang, X. T. Wei, Y. H. Chen, C. K. Duan, and M. Yin, J. Rare Earth 31, 27 (2013).

[46] J. Ueda and S. Tanabe, J. Appl. Phys. 110, (2011).

[47] G. M. Yang, S. M. Zhou, H. Lin, and H. Teng, Physica B-Condensed Matter 406, 3588 (2011).

[48] H. Zhang, X. Y. Liu, F. Y. Zhao, L. H. Zhang, Y. F. Zhang, and H. Guo, Opt. Mater. 34, 1034 (2012).

[49] J. Y. Sun, Y. N. Sun, C. Cao, Z. G. Xia, and H. Y. Du, Appl. Phys. B-Lasers and Optics 111, 367 (2013).

[50] J. D. Chen, H. Guo, Z. Q. Li, H. Zhang, and Y. X. Zhuang, Opt. Mater. 32, 998 (2010).

[51] H. J. Zhang, Y. H. Wang, and L. L. Han, J. Appl. Phys. 109, (2011).

[52] H. Lin, X. H. Yan, and X. F. Wang, Mater. Sci. and Eng. B-Adv. Func. Solid-State Mater. 176, 1537 (2011).

[53] H. S. Nalwa, L. S. Rohwer, Handbook of luminescence, display materials, and devices, American Scientific Publishers, Stevenson Ranch, Calif. , (2003).

[54] S. T. Aruna and A. S. Mukasyan, Current Opinion in Solid State \& Mater. Sci. 12, 44 (2008).
[55] X. A. Y. Huang, X. A. H. Ji, and Q. Y. A. Zhang, J. Amer. Ceramic Soc. 94, 833 (2011).

[56] Q. Y. Zhang, C. H. Yang, and Y. X. Pan, Appl. Phys. Lett. 90, (2007).

[57] X. Y. Huang and Q. Y. Zhang, J. Appl. Phys. 107, (2010).

[58] L. Y. Wu, X. N. Tian, X. T. Wei, Y. H. Chen, and M. Yin, J. Rare Earth 30, 1213 (2012).

[59] N. Rakov and G. S. Maciel, J. Appl. Phys. 110, (2011).

[60] Sheetal, V. B. Taxak, Mandeep, and S. P. Khatkar, J. Alloys Compd. 549, 135 (2013).

[61] V. B. Taxak, Sheetal, Dayawati, and S. P. Khatkar, Current Appl. Phys. 13, 594 (2013).

[62] Q. Y. Zhang and X. F. Liang, J. Soc. Inform. Display 16, 755 (2008).

[63] U. Rambabu and S. D. Han, Ceramics Inter. 39, 1603 (2013).

[64] B. C. Cheng, L. T. Fang, Z. D. Zhang, Y. H. Xiao, and S. J. Lei, J. Phys. Chem. C 115, 1708 (2011).

[65] H. Chander, Proc. of ASID, 11 (2006).

[66] J. L. Yuan, X. Y. Zeng, J. T. Zhao, Z. J. Zhang, H. H. Chen, and X. X. Yang, J. Phys. D-Appl. Phys. 41, (2008).

[67] L. M. Chen, Y. M. Long, Y. M. Qin, W. F. Li, Mater. Lett. 102, 59 (2013).

[68] W. L. Feng, Y. Jin, Y. Wu, D. F. Li, and A. K. Cai, J. Lumin. 134, 614 (2013).

[69] T. Ogi, A. B. D. Nandiyanto, W. N. Wang, F. Iskandar, and K. Okuyama, Chem. Engineer. J. 210, 461 (2012).

[70] W. Shi, A. Feng, H. B. Tang, Z. L. Ding, Y. Q. Ma, M. Z. Wu, and G. Li, Opt. Mater. 35, 609 (2013).

[71] G. Zhu, X. J. Wang, H. L. Li, L. K. Pan, H. C. Sun, X. J. Liu, T. Lv, and Z. Sun, Chem. Commun. 48, 958 (2012).

[72] Z. H. Zhang, J. G. Feng, and Z. L. Huang, Particuol. 8, 473 (2010).

[73] Q. Zhang, Q. Y. Meng, and W. J. Sun, Opt. Mater. 
35, 915 (2013).

[74] H. Lai, A. Bao, Y. M. Yang, Y. C. Tao, H. Yang, Y. Zhang, and L. L. Han, J. Phys. Chem. C 112, 282 (2008).

[75] Q. B. Li, J. M. Lin, J. H. Wu, Z. Lan, Y. Wang, F. G. Peng, and M. L. Huang, Electrochimica Acta 56, 4980 (2011).

[76] C. X. Li, J. Yang, P. P. Yang, H. Z. Lian, and J. Lin, Chem. Mater. 20, 4317 (2008).

[77] J. X. Zhang, Q. Xiao, and Y. L. Liu, J. Rare Earth 31, 342 (2013).

[78] J. S. Liao, D. Zhou, H. Y. You, H. R. Wen, Q. H. Zhou, and B. Yang, Optik. 124, 1362 (2013).

[79] Z. H. Xu, C. X. Li, P. P. Yang, C. M. Zhang, S. S. Huang, and J. Lin, Cryst. Growth Des. 9, 4752 (2009).

[80] X. P. Chen, X. Y. Huang, and Q. Y. Zhang, J. Appl. Phys. 106, (2009).

[81] C. X. Li, Z. W. Quan, J. Yang, P. P. Yang, and J. Lin, Inorg. Chem. 46, 6329 (2007).

[82] J. Chen, H. Zhang, F. Li, and H. Guo, Mater. Chem. Phys. 128, 191 (2011).

[83] T. Grzyb, M. Runowski, A. Szczeszak, and S. Lis, J. Sol. State Chem. 200, 76 (2013).

[84] Q. Q. Du, G. J. Zhou, J. Zhou, X. Jia, and H. F. Zhou, J. Alloys Compd. 552, 152 (2013).

[85] S. Lepoutre, D. Boyer, and R. Mahiou, J. Lumin. 128, 635 (2008).

[86] X. Q. Cao, T. Wei, Y. H. Chen, M. Yin, C. X. Guo, and W. P. Zhang, J. Rare Earth 29, 1029 (2011).

[87] Y. J. Peng, J. Liu, K. Zhang, H. Luo, J. H. Li, B. Xu, L. X. Han, X. J. Li, and X. B. Yu, Appl. Phys. Lett. 99, (2011).

[88] P. Salas, R. Borja-Urby, L. A. Diaz-Torres, G. Rodriguez, M. Vega, and C. Angeles-Chavez, Mater. Sci. Engin. B-Adv. Funct. Solid-State Mater. 177, 1423 (2012).

[89] H. Y. Sun, X. Zhang, and Z. H. Bai, J. Rare Earth 31, 231 (2013).
[90] J. J. Zhou, Y. Teng, X. F. Liu, S. Ye, Z. J. Ma, and J. R. Qiu, Phys. Chem. Chem. Phys. 12, 13759 (2010).

[91] X. R. Cheng, L. Su, Y. Q. Wang, X. Zhu, X. T. Wei, and Y. Y. Wang, Opt. Mater. 34, 1102 (2012).

[92] M. H. Qu, R. Z. Wang, Y. Chen, Y. Zhang, K. Y. Li, and H. Yan, J. Lumin. 132, 1285 (2012).

[93] M. H. Qu, R. Z. Wang, Y. Zhang, K. Y. Li, and H. Yan, J. Appl. Phys. 111, (2012).

[94] J. J. Zhou, Y. Teng, S. Ye, G. Lin, and J. R. Qiu, Opt. Mater. 34, 901 (2012).

[95] S. F. Zou, Z. L. Zhang, F. Zhang, and Y. L. Mao, J. Alloys Compd. 572, 110 (2013).

[96] S. Ye, B. Zhu, J. X. Chen, J. Luo, and J. R. Qiu, Appl. Phys. Lett. 92, (2008).

[97] J. J. Zhou, Y. X. Zhuang, S. Ye, Y. Teng, G. Lin, B. Zhu, J. H. Xie, and J. R. Qiu, Appl. Phys. Lett. 95, (2009).

[98] H. L. Wen and P. A. Tanner, Opt. Mater. 33, 1602 (2011).

[99] Q. Zhang, X. F. Liu, S. Ye, B. Zhu, Y. B. Qiao, G. P. Dong, B. Qian, D. P. Chen, Q. L. Zhou, and J. R. Qiu, IEEE Photonics Technol. Lett. 21, 1169 (2009).

[100] B. Xu, B. Yang, Y. P. Zhang, H. P. Xia, and J. H. Wang, J. Rare Earth 31, 164 (2013).

[101] Y. X. Zhuang, Y. Teng, J. J. Zhou, S. Ye, X. F. Liu, G. Lin, J. Ruan, and J. R. Qiu, J. Opt. Soc. Amer. B-Opt. Phys. 26, 2185 (2009).

[102] M. M. Smedskjaer, J. R. Qiu, J. Wang, and Y. Z. Yue, Appl. Phys. Lett. 98, (2011).

[103] B. C. Rowan, L. R. Wilson, and B. S. Richards, IEEE J. Selected Topics in Quantum Electronics 14, 1312 (2008).

[104] J. C. Goldschmidt, P. Loper, S. Fischer, S. Janz, M. Peters, S. W. Glunz, G. Willeke, E. Lifshitz, K. Kramer, and D. Biner, in: Optoelectronic and Microelectronic Materials and Devices, (2008).

[105] W. Shockley and H. J. Queisser, J. Appl. Phys. 32, 510 (1961). 
[106] T. Trupke, M. A. Green, and P. Wurfel, J. Appl. Phys. 92, 1668 (2002).

[107] E. Klampaftis, D. Ross, K. R. McIntosh, and B. S. Richards, Sol. Energ. Mat. Sol. C 93, 1182 (2009).

[108] D. L. Dexter, J. Chem. Phys. 21, 836 (1953).

[109] F. S. Ham, W. W. Piper, and J. A. Deluca, B Am. Phys. Soc. 19, 258 (1974).

[110] Sommerdi. Jl, A. Bril, J. A. D. Poorter, and R. E. Breemer, Philips Res. Rep. 29, 13 (1974).

[111] A. Le Donne, S. K. Jana, S. Banerjee, S. Basu, and S. Binetti, J. Appl. Phys. 113, (2013).

[112] J. Y. Chen, C. K. Huang, W. B. Hung, K. W. Sun, and T. M. Chen, Sol. Energ. Mat. Sol. C 120, 168 (2014).

[113] E. Cattaruzza, M. Mardegan, T. Pregnolato, G. Ungaretti, G. Aquilanti, A. Quaranta, G. Battaglin, and E. Trave, Sol. Energ. Mat. Sol. C 130, 272 (2014).

[114] Y. C. Chen and T. M. Chen, J Rare Earth 29, 723 (2011).

[115] Y. C. Chen, W. Y. Huang, and T. M. Chen, J. Rare Earth 29, 907 (2011). 